\title{
REVISTA
}

\section{REÚSO DE ÁGUA DE CHUVA PARA FINS NÃO POTÁVEIS: PLANEJAMENTO DE INTERVENÇÃO PEDAGÓGICA E REFLEXÕES SOBRE A EDUCAÇÃO PARA A SUSTENTABILIDADE NO ENSINO TÉCNICO}

\author{
RAINWATER REUSE FOR NON-POTABLE PURPOSES: PEDAGOGICAL \\ INTERVENTION PLANNING AND REFLECTIONS ON SUSTAINABILITY \\ EDUCATION IN TECHNICAL TEACHING
}

\author{
$1^{*}$ Alexandre Fiorotti \\ ${ }^{2}$ Octávio Cavalari Júnior \\ ${ }^{1}$ Instituto Federal do Espírito Santo. E-mail: alexandre.fiorotti@ifes.edu.br \\ ${ }^{2}$ Instituto Federal do Espírito Santo. E-mail: cavalarioc@ifes.edu.br \\ *Autor de correspondência
}

Artigo submetido em 29/01/2021, aceito em 15/04/2021 e publicado em 05/05/2021.

Resumo: Este artigo descreve o planejamento de uma prática educativa do tipo intervenção pedagógica, que propõe aos alunos estudar formas de captar e reutilizar a água de chuva para fins não potáveis, a partir do exemplo observado em sua própria casa. Objetiva auxiliar os alunos do $2^{\circ}$ ano do Curso Técnico de Edificações Integrado ao Ensino Médio a compreender a importância de reaproveitar a água de chuva em uma edificação residencial. Nesse sentido, desperta para a urgência de estabelecer padrões de consumo menos impactantes para o meio ambiente no setor da construção civil, ramo em que esses futuros profissionais irão atuar no mercado de trabalho. Inspira-se na tendência pedagógica progressista libertadora de Paulo Freire e na Teoria Sociointeracionista de Vygotsky. Utiliza Metodologia Ativa do tipo Aprendizagem Baseada na Resolução de Problemas, pois propõe, a partir da observação do telhado de uma casa, a gravação de um vídeo e a montagem de painel interativo como resposta aos questionamentos formulados pelo professor. Pretende analisar a intervenção pedagógica por meio da observação direta do comportamento dos alunos e interpretação das respostas postadas, dos vídeos e do painel digital. Conclui que este tipo de intervenção pedagógica possui potencial para ser adotado no ensino de disciplinas do Curso Técnico, contribuindo para o despertar crítico dos alunos para a educação para a sustentabilidade.

Palavras-chave: sustentabilidade; educação para a sustentabilidade; reúso de água de chuva; intervenção pedagógica.

\begin{abstract}
This article describes the planning of an educational practice of the pedagogical intervention type, which proposes to students to study ways to capture and reuse rainwater for nonpotable purposes, from the example observed in their own home. It aims to help 2nd year students of the Technical Course of Constructions Integrated to High School in order to understand the importance of reusing rainwater in a residential building. In this sense, it awakens to the urgency of establishing less impacting consumption patterns for the environment in the construction sector, a branch in which these future professionals will work in the labor market. It is inspired by Paulo Freire's liberating progressive pedagogical tendency and Vygotsky's Socio-interactionist Theory. This work is based on the Active Methodology of Learning Based on Problem Solving, because it proposes,
\end{abstract}


from the observation of the roof of a house, the recording of a video, and the assembly of an interactive panel, as an answer to the questions asked by the teacher. It intends to analyze the pedagogical intervention through direct observation of the behavior of the students and interpretation of the responses posted, the videos and the digital panel. It concludes that this type of pedagogical intervention has the potential to be adopted in the teaching of technical course, disciplines, contributing to the critical awakening of students to education for sustainability.

Keywords: sustainability; education for sustainability; reuse of rainwater; pedagogical intervention.

\section{INTRODUÇÃO}

As primeiras décadas do Século XXI vem mostrando uma série de mudanças nos padrões climáticos atribuídas principalmente às atividades humanas e exploração predatória dos recursos naturais.

Para fazer frente a essas questões, as Organização das Nações Unidas, definiram 17 Objetivos de Desenvolvimento Sustentável (ODS) que são: “[...] um apelo global à ação para acabar com a pobreza, proteger o meio ambiente e o clima e garantir que as pessoas, em todos os lugares, possam desfrutar de paz e de prosperidade" (NAÇÕES UNIDAS BRASIL, 2020, p. 1).

O Objetivo 6, denominado "água potável e saneamento" define como prioridade até 2030, aumentar a eficiência do uso da água em todos os setores, garantir a retirada sustentável, assegurar o abastecimento de água doce e diminuir o número de pessoas que sofrem com a escassez desse recurso natural (NAÇÕES UNIDAS BRASIL, 2020).

No presente trabalho, propõe-se uma prática educativa de intervenção pedagógica (de natureza progressista libertadora), que convida os alunos a estudar formas de captar e reutilizar a água de chuvas, a partir do exemplo observado em sua própria casa. Portanto, trata-se de um tema relevante na atualidade, pois a água advinda do reúso pode diminuir o consumo deste bem natural, além de servir como um recurso hídrico complementar, e desta maneira, impactar menos as fontes de captação de água (REZENDE; TECEDOR, 2017).

$\mathrm{O}$ interesse em pesquisar o tema sustentabilidade em edificações surgiu a partir da docência na disciplina Elementos Prediais, ministrada aos alunos do curso Técnico de Edificações integrado ao ensino médio do Instituto Federal do Espírito Santo (Ifes), campus Nova Venécia. Essa matéria é ministrada no segundo ano desse curso. A média de idade dos alunos é de 16 e 17 anos.

O campus do Ifes Nova Venécia localiza-se na região noroeste do Estado do Espírito Santo, região de clima quente, com altas temperaturas e histórico de ocorrências de secas prolongadas e por vezes, enchentes (INSTITUTO CAPIXABA DE PESQUISA ASSISTÊNCIA TÉCNICA E EXTENSÃO RURAL, 2020). Esses ciclos climáticos naturais de secas e enchentes, que ocorrem naturalmente quase todos os anos, são parte do cotidiano dos alunos e professores.

A partir dessa realidade descrita acima e do contato com a disciplina Elementos Prediais, percebeu-se a importância em aprofundar o tema sustentabilidade, e investigar maneiras alternativas para transmitir esse conteúdo aos alunos, abordando especificamente a captação de água de chuvas em residências.

Com este trabalho, também pretende-se pesquisar de que maneira o ensino deste conteúdo é capaz de despertar e de transformar a percepção dos alunos com relação ao tema sustentabilidade. 
Nesse sentido, essa investigação tem como conceito central a ideia de "educação para a sustentabilidade", presente no trabalho de Lima (2003). Segundo esse autor, o discurso sobre sustentabilidade apresenta várias matrizes ideológicas.

A primeira matriz, que corresponde ao discurso oficial da sustentabilidade, defende que é possível conciliar os interesses do mercado (focado na expansão da economia) com a preservação ambiental, desenvolvendo tecnologias limpas, capazes de reduzir o consumo de recursos naturais, os resíduos e ainda melhorar a produtividade (LIMA, 2003). Contudo, o foco deste trabalho assenta-se na chamada segunda matriz interpretativa, que incorpora outros conceitos.

Segundo Lima (2003), essa segunda matriz interpretativa pode ser entendida como multidimensional, pois prioriza a equidade social e o papel da sociedade civil na transição para a sustentabilidade social. Além disso, essa matriz ideológica tece profundas críticas à civilização capitalista ocidental, ao mito do progresso, e ao consumismo.

Assim, despertou-se o interesse no seguinte problema de pesquisa: É possível trabalhar o conceito de educação para a sustentabilidade com os alunos do curso Técnico de Edificações integrado ao ensino médio, a partir da observação do sistema de captação de água de chuva de sua própria casa?

A proposta é fazer com que os alunos trabalhem a percepção do espaço geográfico e do clima, da região em que vivem e reflitam criticamente sobre os conceitos de sustentabilidade e sobre os padrões de consumo da sociedade.

Essa diretriz vai ao encontro da tendência pedagógica adotada para a realização da prática educativa, no caso a Pedagogia Progressista Libertadora, não por esta ser uma tendência voltada a este tema específico, mas por ela, em seu cerne, adotar práticas a estimular criticidade do educando, contrapondo a realidade deste a uma nova possível realidade, e a uma nova estrutura do conhecimento, com o educando capaz de reordenar e reelaborar novos conhecimentos (LIBÂNEO, 2003).

Considerando que o setor de construção civil é um dos grandes consumidores de insumos, e também um grande causador de impactos ambientais, percebe-se que esse assunto é (ou poderá ser) abordado de forma transversal no curso técnico em edificações.

Portanto, a prática educativa proposta neste relatório consiste em estudar a captação e reuso de água de chuva para fins não potáveis, objetivando a redução do consumo de água, além de propor mecanismos para coletar e interpretar dados e, assim, poder avaliar o percurso dos alunos.

Pretende-se também identificar outros aspectos multidisciplinares inerentes ao projeto, como por exemplo, calcular a superfície do telhado, identificar a incidência de chuvas na região em que mora, observar qual seria o corpo receptor da água pluvial do seu bairro (qual rio e bacia hidrográfica); qual o tipo de pavimentação da rua e bairro em que sua casa está localizada; qual tipo de material utilizado para fabricação das calhas e reservatório de água de chuva.

Esta pesquisa pautou-se na leitura do trabalho de Freire (2002) e Libâneo (1993), especialmente com relação às teorias e tendências pedagógicas.

No tema central da pesquisa, destaca-se o trabalho de Lima (2003), que analisa as implicações do discurso da sustentabilidade na educação.

O trabalho de Libâneo (1990) também foi fundamental para $\mathrm{o}$ entendimento dos objetivos de Aprendizagem, bem como o trabalho de Luckesi (2000), com relação à construção da avaliação. 
Para o entendimento dos conceitos de sala de aula interativa, foi primordial o contato com o trabalho de Santos e Silva (2020). Da mesma maneira, a obra de Damiani et al. (2013) foram referência para o estudo das pesquisas tipo intervenção.

Por fim, o trabalho de Zanetti Neto (2019) serviu para o estudo das práticas de ensino adotadas neste trabalho.

Assim, o objetivo geral desta pesquisa é: Propor uma prática educativa de intervenção pedagógica para auxiliar os alunos do curso Técnico de Edificações a compreender a importância de reaproveitar a água de chuva para fins não potáveis em uma edificação residencial.

Ao incentivar a captação e reutilização de água de chuva em edificações residenciais, espera-se poder ensinar formas de reduzir os impactos da captação de água potável na bacia hidrográfica, durante períodos de estiagem prolongada. Vale ressaltar que a região noroeste do Espírito Santo, onde localizase o campus Nova Venécia, enfrenta periodicamente períodos de altas temperaturas e déficit hídrico.

Por outro lado, ao ensinar como implantar sistemas de captação e armazenamento de água de chuva, esperase poder contribuir indiretamente para reduzir o aporte de água no sistema pluvial das cidades, notadamente em áreas muito urbanizadas, onde o solo é largamente impermeabilizado e, assim, difundir nesses futuros profissionais o conhecimento de um sistema que pode, potencialmente, auxiliar a reduzir a gravidade das enchentes em áreas densamente construídas.

Por fim, espera-se poder contribuir para aprimorar a prática de ensino na disciplina Elementos Prediais, ou difundir a utilização dessa metodologia proposta para outras disciplinas que abordem $o$ conteúdo de sustentabilidade em edificações.

\section{REFERENCIAL TEÓRICO}

\subsection{TENDÊNCIA PEDAGÓGICA PROGRESSISTA LIBERTADORA}

No que tange às práticas e teorias de ensino e aprendizagem, esta pesquisa tem como fundamento teórico a tendência pedagógica progressista libertadora, proposta por Paulo Freire, mesmo não sendo próprio desta pedagogia uma proposta formal de ensino, ou seja, não é visto como prática usual nas escolas e nas ações pedagógicas (LIBÂNEO, 2003).

Contudo, acredita-se que isto não exclui a tentativa, embora desafiadora, de trazer para ações escolares a visão libertadora que esta tendência pedagógica carrega.

Para Libâneo (1993), tanto a educação tradicional dita bancária, quanto a educação renovada, que buscaria a liberdade psicológica do indivíduo, podem ser descritas como domesticadoras, já que não ajudam na superação da realidade social e da opressão. A educação libertadora, em oposição, questiona de fato a realidade das relações do homem com a natureza e com os seus semelhantes para transformar a realidade, sendo assim, uma educação crítica.

Autores como Libâneo (2003) observam que, na pedagogia progressista libertadora, o importante em relação aos conteúdos de ensino não é a transmissão da teoria, mas fazer surgir nos estudantes uma nova postura para enfrentar a experiência vivida. Os temas geradores devem ser trazidos "[...] da problematização prática de vida dos educandos" (LIBÂNEO, 1993, p. 33).

Ainda segundo o autor citado acima, aprender é uma ação de entendimento da realidade vivida pelo aluno e só se realiza plenamente quando se aproxima criticamente desse contexto.

Os métodos de ensino desta pedagogia baseiam-se na construção de um 
diálogo, e em uma relação horizontal entre professor e alunos. Os passos da aprendizagem consideram importante a troca de experiências entre os participantes, partindo da experiência individual vivida, até alcançar um nível mais crítico de conhecimento (LIBÂNEO, 1993).

Assim, a proposta de prática pedagógica apresentada consiste em instigar o aluno a observar como é feita a captação de água de chuva na sua casa, apresentar, posteriormente, como funciona um sistema de captação e reúso de água de chuva e, então, pensar criticamente sobre vários outros aspectos multidisciplinares relativos ao tema. Com isso, espera-se que a partir de sua curiosidade ingênua, o aluno possa pensar sobre sustentabilidade.

Conclui-se, como é descrito nesta teoria pedagógica, que "aprender é um ato de conhecimento da realidade concreta, isto é, da situação real vivida pelo educando, e só tem sentido se resulta de uma aproximação crítica dessa realidade" (LIBÂNEO, 2003 p. 10).

\subsection{TEORIA DA APRENDIZAGEM SOCIOINTERACIONISTA}

A proposta apresentada nesta pesquisa se inspira nos conceitos definidos por Lev Semyonovich Vygotsky, criador da Teoria Sociointeracionista.

Para Sgarbi (2020), Vygotsky considerava que, apesar de ter bases biológicas, a construção do pensamento da criança era fortemente influenciada pela relação com o meio, intermediado pelas relações estabelecidas entre o sujeito e o seu contexto social. Então, o desenvolvimento da mente acontecia como consequência dessas interações sociais.

Os principais conceitos desenvolvidos por esta teoria da aprendizagem são: as ideias espontâneas e não espontâneas, a mediação e a Zona de Desenvolvimento Proximal.
Para Vygotsky existem as ideias espontâneas e as ideias não espontâneas. Durante os anos em que vai à escola, a criança não abandona seus conceitos iniciais chamados de espontâneos, mas vai a partir desses conceitos, e por meio da comparação e do pensamento lógico, em direção aos conceitos abstratos chamados de não espontâneos. Os conceitos espontâneos, ou seja, que surgem a partir do ambiente social, transformam-se em uma nova relação cognitiva com o mundo (SGARBI, 2020).

Para o autor citado acima, o homem utiliza diversos sistemas simbólicos para se relacionar com o mundo. De maneira semelhante, a construção do conhecimento acontece com a mediação de outros sujeitos, surgindo então, o conceito de mediação.

A Zona de Desenvolvimento Proximal (ZDP) é um conceito surgido quando se mensura a distância entre a capacidade de uma criança realizar atividades sozinhas, sem auxílio do professor (chamado de nível de desenvolvimento real), e quando a criança desenvolve atividades sob a supervisão de adultos ou com colaboração de colegas (chamado de nível de desenvolvimento potencial). O Nível de desenvolvimento potencial é um importante campo de atuação para os professores, pois pode contribuir para o desenvolvimento de habilidades dos estudantes, com a ajuda de trabalho em equipe, ou com a colaboração de um orientador (SGARBI, 2020).

Assim, o exercício proposto neste trabalho se insere na teoria sociointeracionista de Vygotsky, pois propõe-se que o aluno observe um exemplo concreto existente em sua realidade (o funcionamento de um sistema de captação de água de chuva, ou uma calha de chuva instalada no telhado de sua casa) e, por meio da mediação do professor, adquira novos conhecimentos sobre sustentabilidade. 
Assim, esses indivíduos são estimulados a trabalhar em grupo e a refletir sobre a realidade social em que vivem e efetivamente transformá-la.

Pretende-se também que os alunos alcancem o nível de desenvolvimento potencial, por meio da construção coletiva de vídeos e de um painel interativo, sob a orientação do professor.

\subsection{PRÁTICA PEDAGÓGICA}

A proposta de investigação deste trabalho pode ser definida também como pesquisa tipo intervenção.

Para Damiani et al. (2013) pesquisa tipo intervenção são investigações que dizem respeito ao planejamento e implantação de mudanças que visam produzir avanços, melhorias, na aprendizagem dos alunos que participam, sendo que os resultados devem ser posteriormente avaliados.

Ainda segundo Damiani et al. (2013), pesquisas do tipo intervenção pedagógica são aplicadas, ou seja, têm como finalidade contribuir para a solução de problemas práticos. Elas se opõem às pesquisas básicas, que objetivam ampliar conhecimentos, sem preocupação com seus possíveis benefícios práticos.

Para que o relato de uma pesquisa possa ser chamado de intervenção, de acordo com Damiani et al. (2013), entende-se que dois componentes metodológicos são essenciais: o método da intervenção e o método da avaliação da intervenção. Deve haver clareza na descrição da metodologia utilizada e na avaliação propriamente dita, para que o leitor possa ter clareza de que as intervenções são também investigações.

A leitura do trabalho de Seniciato e Cavassan (2004) ajudou a compreender a importância do trabalho de campo para despertar nos alunos a responsabilidade pela preservação dos ecossistemas.
Para os referidos autores indicados acima, se o aluno conseguir compreender o funcionamento dos ecossistemas, ele terá mais capacidade de decidir sobre os problemas ambientais e sociais do local em que vive, quando for a hora. Além disso, as pessoas tendem a respeitar e preservar o que conhecem. Por outro lado, o desconhecimento pode levar a um entendimento errado dos fatos $\mathrm{e}$ da realidade.

De maneira semelhante, Zanetti Neto (2020) considera que a atividade de campo tem potencial para trazer sensações que não surgem em sala de aula, como a experiência da turma de momentos descontraídos, a vivência de novos lugares e espaços e a estética. Nessas atividades, a questão filosófica da estética faz com que se aliem a dimensão sensível e cognitiva. Portanto, essa prática pedagógica aciona a memória de longo prazo.

Considera-se que esses pressupostos também serão válidos para visita em campo em ecossistemas urbanos, pois ao visitarem uma edificação e conhecerem o funcionamento de um sistema de captação e reúso de água de chuva implantado na região em que vivem, poderão ser despertadas sensações e conhecimentos do mundo real úteis ao desenvolvimento cognitivo dos alunos.

\subsection{APRENDIZAGEM BASEADA NA RESOLUÇÃO DE PROBLEMAS (ABRP)}

Esta pesquisa pode ser classificada como uma Metodologia Ativa do tipo Aprendizagem Baseada na Resolução de Problemas (ABRP), pois, conforme Zanetti Neto (2019, p. 82), esse modelo: “[...] tem a preocupação de que a prática de ensino mobilize, nos estudantes, as dimensões relativas ao desenvolvimento de habilidades e também das atitudes".

$$
\text { Vale lembrar que na ABRP o }
$$
objetivo é mobilizar as habilidades e conhecimentos dos estudantes para analisar e pensar sobre um problema colocado pelo 
professor, baseado em situações reais. O trabalho, de acordo com essa proposta de ensino, deve ser realizado colaborativamente, ou seja, em grupos, para desenvolver nos alunos a comunicação e o espírito de equipe (ZANETTI NETO, 2019).

Ainda segundo o autor anteriormente citado, o "problema" na ABRP se baseia em fatos reais $e$ complexos. Assim, não haverá uma resposta única.

Por ser aberto, o problema será o ponto de partida, em que os estudantes irão adquirir novos conhecimentos e habilidades, por meio de investigação, desenvolvimento de hipóteses e procura de soluções.

Para Zanetti Neto (2019, p. 83), a organização de uma atividade de ABRP possui as seguintes etapas:

a) apresentação do contexto
problemático;

b) formulação de questões;

c) seleção, hierarquização e distribuição das questões pelos diversos grupos;

d) pesquisa de informação;

e) organização da informação;

f) elaboração do produto final;

\subsection{TECNOLOGIA EDUCACIONAL}

Para Santos e Silva (2014), transmitir, memorizar e repetir é forma de ensinar mais comum nas escolas e universidades em todo o mundo. Muitos já perguntaram sobre a eficácia dessa prática pedagógica, mas pouco se trabalhou para alterá-la.

Com o paradigma da sociedade da informação e da cibercultura, a atual geração digital, no qual os alunos contemporâneos se inserem, passou a ser menos passiva para receber conteúdos em sala de aula, já que está exposta a inúmeros dispositivos de aprendizagem, como a televisão, o computador, os videogames, que possuem recursos de conectividade e, muitas vezes, permitem a produção de conteúdo próprio.

Por estar acostumada a interagir com os meios de comunicação, essa geração não se sente estimulada a acompanhar aulas expositivas tradicionais, que não permitem a interação (SANTOS; SILVA, 2014).

Essa atitude diante da mensagem é sua exigência de uma nova sala de aula, seja na educação básica e na universidade, seja na educação presencial e a distância. Nesse contexto sociotécnico os professores e professoras estão cada vez mais compelidos à utilização de novas tecnologias de informação e de comunicação, mas permanecem pouco atentos à necessidade de modificar a sala de aula centrada na pedagogia da transmissão (SANTOS; SILVA, 2014, p. 47).

Paiva et al. (2011) verificaram que esses jovens possuem as seguintes características: habilidade para ler imagens visuais; aprendem melhor por descoberta do que ouvindo; mudam o foco de atenção rapidamente de uma tarefa para outra e muitas vezes escolhem não prestar atenção nos assuntos que não têm interesse; possuem tempo de resposta rápido $\mathrm{e}$ também esperam respostas rápidas.

Por outro lado, para esses mesmos autores, essa geração amplificou o imediatismo já presente no comportamento dos jovens e apresenta dificuldades em gastar um tempo maior em temas específicos.

Portanto, é preciso que os professores estejam atentos ao espírito da época, ou seja, para o surgimento da cultura comunicacional emergente e alterem o ambiente de aprendizagem da sala de aula (SANTOS; SILVA, 2014). 
Para os referidos autores já citados, ao contrário do sistema de ensino tradicional, em que a mensagem era unidirecional, linear, centrada na figura do professor e onde os alunos possuíam papel de assimiladores passivos, a modalidade de comunicação interativa difundida pelo uso de novas tecnologias possui mensagem viva, modificável.

O Professor irá fornecer aos alunos caminhos para que ele possa percorrer e buscar o conhecimento. Por sua vez, os alunos se tornam manipuladores da mensagem como autores e cocriadores (SANTOS; SILVA, 2014).

Então, o professor, ao propor o conhecimento, deve estar atento aos seguintes pontos: usar como exemplo o hipertexto e trabalhar com a perspectiva da participação e interação dos alunos, estando atentos a alguns princípios básicos como por exemplo, proporcionar trabalhos colaborativos; fazer uso de diferentes mídias; provocar situações de inquietação criadora; planejar percurso colaborativos ao estilo de hipertextos e mobilizar a experiência do conhecimento dos alunos (SANTOS; SILVA, 2014).

Segundo Paiva et al. (2011), os educadores e escolas devem observar que não adianta apenas investir na utilização de softwares e novas tecnologias se a maneira de ensinar o aluno continua centrada na transmissão unilateral de informação. Para os referidos autores, o essencial não é a tecnologia e a ferramenta utilizada pela escola, mas a pedagogia utilizada, que deve incluir a participação e cooperação no caminho de construção do conhecimento.

Portanto, partindo dos conceitos expostos acima, a prática de intervenção proposta irá adotar alguns recursos de comunicação interativa, de maneira a proporcionar que os alunos percorram e construam seu próprio caminho para o conhecimento, como por exemplo:

a) gravação de vídeos, utilizando smartfones; b) uso de infográfico elaborado pelo professor na aula (programa Genial.ly);

c) pesquisa utilizando a internet;

d) pesquisa utilizando a plataforma youtube;

e) construção de painel interativo (padlet.com);

f) participação em um Fórum de discussão virtual.

A escolha pelo uso de smartfones para a atividade de gravação de vídeo se justifica pela sua ampla difusão e versatilidade, tendo em vista que quase todos possuem o aparelho e já sabem lidar com os principais aplicativos de gravação de vídeo.

O uso do infográfico e da pesquisa na internet são interessantes, pois permitirão que os estudantes acessem durante a aula, ou em casa, o conteúdo e possam revisar os conceitos apresentados pelo professor e incrementar a pesquisa sobre o tema em sites, assistir vídeos do youtube, permitindo maior autonomia $\mathrm{e}$ protagonismo no estudo.

Por fim, a optou-se em elaborar um painel interativo para proporcionar a construção coletiva do conhecimento apresentado, bem como o compartilhamento das ideias pelos alunos.

Os softwares e dispositivos são acessíveis aos estudantes, pois quase todos possuem aparelho celular com acesso à internet, ou possuem facilidade de acesso aos computadores disponibilizados pelo Ifes em seus laboratórios. Além disso, os alunos, em sua maioria, estão habituados a gravar vídeos, realizar pesquisa na rede mundial de computadores e usar aplicativos multimídia.

A construção de painel interativo por meio do aplicativo padlet.com se adequa ao projeto pedagógico proposto, pois se trata de um aplicativo fácil de usar, com comandos intuitivos, além de ser de uso 
gratuito e possuir interface com navegador de internet e vídeos, imagens, por exemplo.

\subsection{INSTRUMENTOS DE PRODUÇÃO DE DADOS}

Além dos instrumentos de produção de dados descritos no item anterior, a análise da intervenção pedagógica proposta será realizada por meio da observação direta do comportamento dos alunos durante as diferentes Ações planejadas.

Para Günter (2006), a observação de comportamento é uma das formas de aproximação que o cientista / pesquisador possui para avaliar os diferentes comportamentos e dos estados subjetivos em pesquisas qualitativas.

Para esse mesmo autor, deve-se atentar para o fato de que na pesquisa qualitativa não existe controle das variáveis externas, sendo todas elas importantes de serem estudadas. Contudo, o pesquisador deverá ter cuidado de selecionar as variáveis mais importantes para serem estudadas.

Ainda segundo Günter (2006), com a observação, o pesquisador pode fazer o registro das manifestações humanas, por meio da escrita em diários, filmes e gravações, possuindo a vantagem de poder demonstrar o realismo da situação estudada.

O pesquisador que utiliza métodos qualitativos deverá, entretanto, atentar-se para o papel da subjetividade do aluno durante a pesquisa, e ter atenção durante as etapas de delineamento; coleta de dados; transcrição; e preparação dos dados para análise específica (GÜNTER, 2006).

O citado autor acima também indica outras maneiras de coletar dados em uma pesquisa qualitativa: a coleta de dados verbais por meio de entrevistas centradas em problema; entrevista narrativa; grupo de discussão; e dados visuais com a observação participante.
Por fim, Günter (2006) alerta que é importante analisar e transcrever adequadamente os dados na pesquisa qualitativa.

Nesse aspecto, o registro e a interpretação das respostas postadas no Fórum de discussão e o material postado no Painel Interativo possuem potencial para uma rica coleta de dados. Espera-se que vídeos gravados também possam se tornar uma ferramenta útil nesse processo.

Durante o desenvolvimento de todas as ações planejadas, o professor deverá utilizar um diário de aula, em que fará as anotações e registrará observações importantes relativas à participação e percepção dos alunos.

\subsection{ANÁLISE DO CLIMA PARA IMPLANTAÇÃO DE SISTEMA DE CAPTAÇÃO E REÚSO DE ÁGUA DE CHUVA}

De acordo com Lamberts, Dutra e Pereira (2014), a captação de águas de chuva pode ser um recurso com grande potencial de uso econômico no Brasil. Após a chuva, a água é captada pelas calhas e é normalmente conduzida para a rede de drenagem pluvial e para as redes de esgoto e, por fim, para um curso d'água ou lagoa. Caso seja feita a interceptação dessa água e instalados filtros e reservatórios, essa água poderia ser reutilizada para irrigação de jardins, limpeza de carros, pisos e descargas.

A análise do clima local pode sugerir vários indicativos de como um projeto deverá ser conduzido.

Conforme mostrado na Figura 1 abaixo, o Estado do Espírito Santo localiza-se na Zona Bioclimática 8 , e de acordo com o Instituto Capixaba de Pesquisa Assistência Técnica e Extensão Rural (2020), a região noroeste do Espírito Santo apresenta média de precipitação anual de $1.000 \mathrm{~mm}$, uma das menores do 
estado, conforme mostrado em seguida na Figura 2.

Figura 1: Zonas Bioclimáticas brasileiras

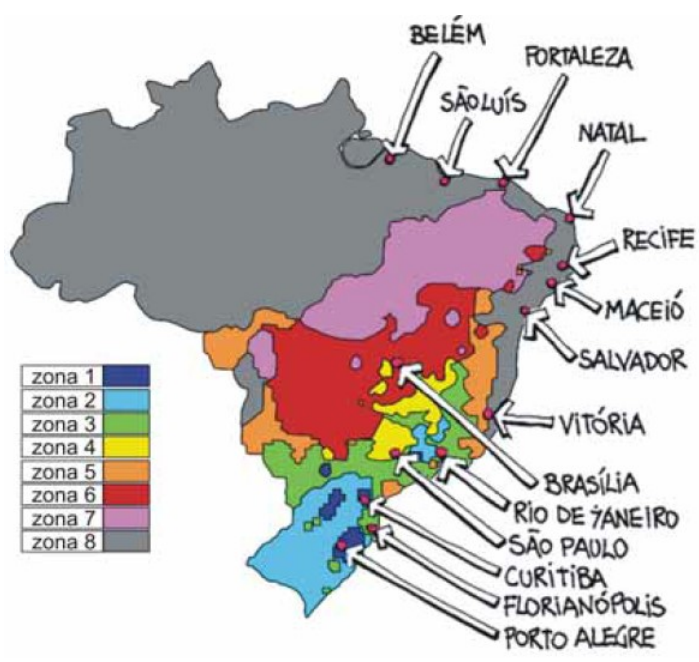

Fonte: Lamberts, Dutra e Pereira (2014)

Figura 2: Mapa de precipitação média anual no Espírito Santo (1984 - 2014)

\section{Média anual de precipitação (1984 a 2014):}

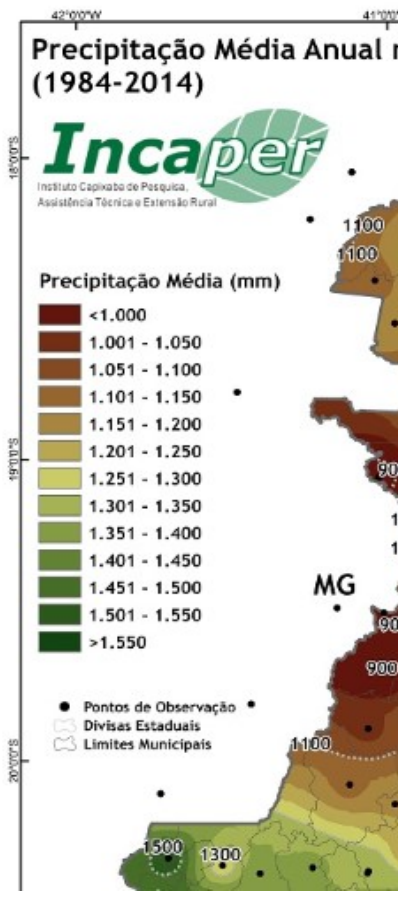

Fonte: Instituto Capixaba de Pesquisa Assistência Técnica e Extensão Rural (2020)
Para Corbela e Corner (2015), a arquitetura bioclimática tem como proposta adequar as edificações ao clima do local em que elas estejam inseridas. Esse tipo de conceito de arquitetura considera as construções como uma espécie de membrana reguladora entre o exterior e o interior do edifício. Assim, para que essa membrana possa ser projetada de maneira eficiente e com economia de recursos naturais, como materiais de construção, energia e água, é necessário que os projetistas conheçam o clima local e suas variações ao longo do ano, para poderem construir habitações como uma "membrana" eficiente.

Estudar o clima, o regime de chuvas, a direção dos ventos, poderá dizer quais estratégias bioclimáticas podem ser mais eficazes em razão do clima e para cada período do ano. Então, ao avaliar todos esses condicionantes, o responsável pelo projeto saberá quais estratégias podem ser mais eficazes para obter o conforto, a eficiência energética da edificação e reduzir o consumo de recursos naturais como a água (LAMBERTS; DUTRA; PEREIRA, 2014).

O campus do Ifes Nova Venécia localiza-se na região noroeste do Estado do Espírito Santo. Para Lamberts, Dutra e Pereira (2014), essa região situa-se na Zona Bioclimática 8 , que se caracteriza pelo clima quente e úmido e por temperaturas altas durante a maior parte do ano.

Além disso, de acordo com o Instituto Capixaba de Pesquisa Assistência Técnica e Extensão Rural (2020), a região enfrenta períodos de secas prolongadas. Por outro lado, em alguns anos, também atravessou períodos de enchentes.

Os requisitos para o aproveitamento de água de chuva de coberturas para fins não potáveis foram obtidos do estudo da NBR 15527/2019 (ASSOCIAÇÃO BRASILEIRA DE NORMAS TÉCNICAS, 2019). 
Essa norma técnica define como fins não potáveis as águas de chuva utilizadas para descargas em bacias sanitárias, reserva técnica de incêndio, sistema de resfriamento a água, irrigação para fins paisagísticos, lavagem de veículos, pisos e uso ornamental (ASSOCIAÇÃO BRASILEIRA DE NORMAS TÉCNICAS, 2019).

O Apêndice I traça um roteiro para ensinar os alunos a dimensionar um reservatório de água, considerando o índice pluviométrico, a superfície do telhado, dentre outras informações.

O Apêndice II apresenta os infográficos que poderão ser enviados aos alunos para o início do desenvolvimento da atividade.

Por fim, o Apêndice III ilustra o Painel Interativo que poderá ser construído ao final da intervenção.

\subsection{APROVEITAMENTO DE ÁGUA DE CHUVA PARA FINS NÃO POTÁVEIS}

Foram realizadas buscas em artigos postados no site https://www.scielo.br/, indicando como descritores: "captação de água de chuva" e "captação de água pluvial". Dessas buscas, foram utilizados dois artigos, escritos por Rezende e Tecedor (2017) e Brandão e Marcon (2018), que foram importantes para analisar a evolução dos métodos de dimensionamento de reservatórios de águas de chuva, bem como a utilização desse método no Brasil.

Segundo Brandão e Marcon (2018) e Rezende e Tecedor (2017), a utilização de águas provenientes da chuva utilizam estruturas já construídas dos edifícios, principalmente os telhados e as calhas. $\mathrm{O}$ reservatório se torna a parte mais cara desse sistema.

Então, para esses autores, um dos maiores desafios para viabilização técnica e financeira de um sistema de coleta de águas de chuva é o correto dimensionamento do reservatório.

No processo de dimensionamento busca-se determinar a capacidade volumétrica capaz de atender a maior demanda possível com o menor custo, pois reservatórios demasiadamente grandes podem ser inviáveis tanto física quanto economicamente. $\mathrm{O}$ reservatório de um sistema de aproveitamento de água de chuva não deve permanecer ocioso por longo período, bem como não pode provocar o desperdício de água pluvial em detrimento ao atendimento da demanda necessária (REZENDE; TECEDOR, 2017, p. 1041).

Para Rezende e Tecedor (2017), países como Inglaterra, Estados Unidos, Alemanha, Austrália e o Japão já pesquisam e utilizam a água de chuva como recurso.

Os mesmos autores descritos acima relatam que historicamente existem registro no Brasil de utilização destes sistemas na região nordeste. Apenas nos últimos anos essa alternativa tem ganhado espaço na região Sudeste e se projeta como alternativa promissora para enfrentar problemas urbanos como as inundações e a falta de água potável em regiões metropolitanas. Então, a captação de água de chuva aumenta a oferta de água para as edificações e diminui potencialmente o consumo de água potável, além de ajudar a combater alagamentos em áreas densamente urbanizadas (REZENDE; TECEDOR, 2017).

Para Finkler (2020), em áreas muito urbanizadas ocorre a diminuição da infiltração de água no solo e, por consequência, diminuição dos níveis do lençol freático por falta de alimentação, diminuindo o escoamento subterrâneo. Essa redução no escoamento subterrâneo pode diminuir o fluxo dos rios e diminuir sua vazão em períodos de seca.

Segundo essa mesma autora, dependendo do grau de urbanização, pode 
ocorrer a descaracterização do recurso hídrico, tornando-o um sistema de drenagem urbana. Em períodos de secas prolongadas, a vazão desses rios pode reduzir consideravelmente, limitando a oferta de água potável e a capacidade desses rios absorverem cargas de poluição.

Nesse cenário de escassez de recursos hídricos, as águas pluviais podem ser usadas (sem necessidade de tratamento) em edificações de uso residencial e comercial, principalmente para usos não potáveis, como descargas de vasos sanitários, manutenção de jardins, pisos e lavagem de carros, e também em indústrias. Esta restrição, com relação à potabilidade, se deve à dificuldade de controlar as fontes de contaminação da água de chuva ao entrar em contato com as coberturas, como poeira, folhas e fezes de animais (REZENDE; TECEDOR, 2017).

A Figura 3 abaixo, mostra os principais componentes e o funcionamento de sistemas de captação e reúso de água de chuva em residências.

Figura 3: Dispositivos para captação e armazenamento de água de chuva para fins não potáveis em residências

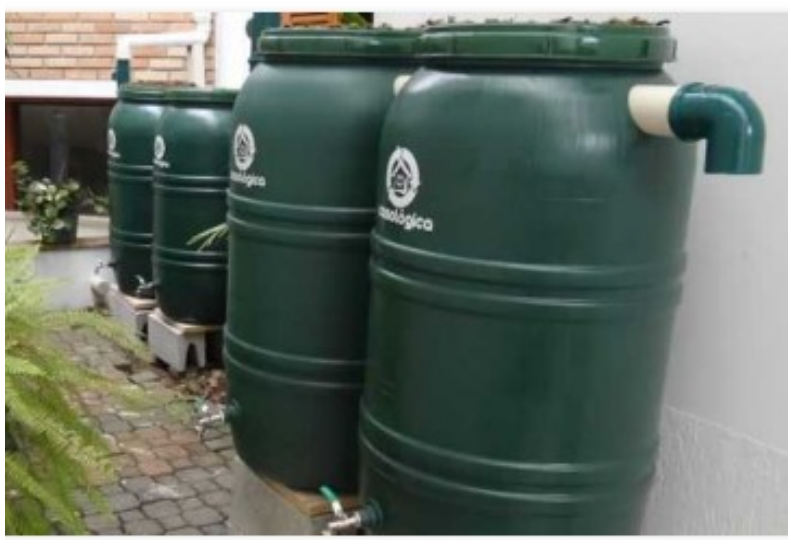

Fonte: Sempresustentavel.com.br. (2020)

Durante o planejamento de um sistema de captação e coleta de água de chuva é necessário estudar as características climáticas da região, principalmente as variações pluviométricas; as demandas previstas para as águas das chuvas; os usos; o tipo de superfície de captação (telhado, piso), podendo ser necessário fazer algum tipo de tratamento, dependendo da qualidade exigida para essa água. É recomendável, descartar as primeiras águas de chuva para evitar contaminação. Esse cuidado inicial pode dispensar até mesmo outros tipos de tratamento químico (REZENDE; TECEDOR, 2017).

Para os referidos autores citados acima, a existência de distintas variáveis em projetos, tais como a superfície de captação, o índice pluviométrico da região, podem resultar na obtenção de volume de água suficiente para abastecer o local por dias, semanas ou até mesmo o ano todo. Normalmente, busca-se obter o maior armazenamento de água pelo menor custo de implantação.

É importante ressaltar que locais muito secos, com baixa precipitação e com períodos de chuva curtos e concentrados ao longo do ano, não favorecem a viabilidade do sistema, enquanto regiões com precipitações bem distribuídas ao longo do ano favorecem a sua implantação (REZENDE; TECEDOR, 2017).

\subsection{EDUCAÇÃO PARA A SUSTENTABILIDADE}

No que se refere ao tema central do trabalho, "a educação para a sustentabilidade", vale apontar a importância e a difusão do assunto na atualidade.

O trabalho de Lima (2003) serviu como eixo condutor dessa pesquisa, devido a interface entre os temas educação e sustentabilidade.

Para Lima (2003), o tema sustentabilidade ganhou destaque nas últimas décadas e se tornou uma palavra mágica, influenciando diversos campos de conhecimento, inclusive a educação. Para 
esse autor, há alguns anos, a expressão educação ambiental passou a ser substituída por "educação para a sustentabilidade".

Ainda segundo o referido autor, o discurso de educação para sustentabilidade é pouco difundido nas práticas educacionais, não obstante a crescente difusão do tema no mundo globalizado.

Historicamente, o discurso de sustentabilidade surgiu na década de 1970, promovido a partir de conferências internacionais sob a tutela da Organização das Nações Unidas (ONU). Nessa época, pode-se citar o trabalho do economista Ignacy Sachs, que criou o conceito de "ecodesenvolvimento" (LIMA, 2003).

O tema sustentabilidade ganhou projeção mundial após a publicação dos trabalhos da Comissão Brundtland no início da década de 1980. Essa comissão, organizada pela ONU, teve como missão estudar a relação entre o meio ambiente e o desenvolvimento e propor novas estratégias para alcançar esses objetivos. O relatório final da comissão, intitulado "nosso futuro comum", foi finalizado em 1987 (LIMA, 2003).

A partir de então, o chamado discurso oficial de sustentabilidade passou a defender a ideia de que era possível conciliar o desenvolvimento econômico, ou seja, os interesses do mercado capitalista, com preservação do meio ambiente, deixando de lado questões de equidade social (LIMA, 2003).

Segundo essa matriz ideológica, é possível crescer economicamente e preservar o meio ambiente, podendo também adaptar novas demandas ambientais e transformá-las em estímulos produtivos. Assim, a partir da tecnologia, é possível melhorar a produtividade e reduzir o consumo de recursos naturais e resíduos (LIMA, 2003).

Contudo, conforme o supracitado autor, nos últimos anos tem ganhado espaço a chamada segunda matriz interpretativa de sustentabilidade. Esse contradiscursso defende os princípios da democracia participativa, da equidade social e não acredita na capacidade do mercado em promover o desenvolvimento sustentado e faz duras críticas ao consumismo e ao capitalismo.

Partindo então dos conceitos da sustentabilidade, estabelecidos na segunda matriz interpretativa, pode-se pensar em uma proposta de educação para a sustentabilidade baseada nos princípios da integração, da interdisciplinaridade, na redução de consumo dos insumos e recursos naturais, na participação social, no estímulo da capacidade crítica dos alunos.

Segundo Lima (2003), essa proposta deverá ainda primar pela autonomia e criatividade dos estudantes, capacitando-os a resolver problemas e realizar mudanças sociais e individuais qualitativas, indo além do conceito raso de sustentabilidade das quais todos já ouviram falar.

Para esse autor citado acima, para que a complexa sociedade atual possa construir uma educação ambiental, é necessário ir além da "sustentabilidade de mercado", e desenvolver a capacidade de aprender, de criar e experimentar novas concepções e práticas de vida, de educação e de convivência que possam suplantar os velhos modelos em esgotamento.

\section{PROCESSOS METODOLÓGICOS}

\subsection{CLASSIFICAÇÃO DA PESQUISA}

Este trabalho classifica-se quanto à sua natureza em aplicado, pois, segundo Gil (2010) e Lakatos e Marconi (2010), objetiva gerar conhecimentos para aplicação prática dirigidos à solução de problemas específicos.

Quanto aos objetivos, ela possui caráter descritivo, pois, segundo Gil (2010), este tipo de pesquisa é utilizado para descrever determinado tipo de população ou fenômeno, principalmente 
por meio de coleta de dados ou observação sistemática.

Com esse trabalho, pretende-se propor uma intervenção pedagógica em alunos do Ensino Técnico, com a gravação de vídeos explicativos e painel colaborativo. Portanto, apresenta caráter exploratório, pois, segundo Gil (2010, p. 41 ), este tipo de pesquisa "[...] tem como objetivo proporcionar maior familiaridade com o problema, com vistas a torná-lo mais explícito ou a construir hipóteses".

A pesquisa é qualitativa, já que se propõe a relatar e interpretar a percepção dos alunos quanto ao tema sustentabilidade.

\subsection{SUJEITOS DA PESQUISA}

A intervenção foi planejada para ser aplicada em duas turmas da Disciplina de Elementos Prediais, do Curso Técnico em Edificações integrado ao Ensino Médio, do Ifes, campus Nova Venécia, durante o segundo semestre do ano de 2020.

A maioria das atividades trabalhadas com os alunos referem-se a projetos que são realizados em grupos, utilizando-se os computadores do laboratório de informática, sempre sob orientação e supervisão do professor da disciplina.

A turma possui 35 alunos, que cursam o período vespertino e possuem idade em torno de 16 e 17 anos. Essa disciplina é dividida em duas turmas (A e B), com respectivamente 18 e 17 alunos cada. Essa divisão ocorre devido à limitação no quantitativo de computadores disponíveis no laboratório de informática.

As atividades propostas para os alunos nesta pesquisa (trabalho em equipe, visita de campo, pesquisa com auxílio da internet, gravação de vídeos e postagem em painel interativo) ocorrerão sempre com a supervisão e orientação do professor da disciplina, de maneira a estimular a participação ativa dos alunos e mediar apropriadamente o processo de aprendizagem.

\section{PROPOSTA DE INTERVENÇÃO PEDAGÓGICA}

A prática educacional proposta será uma intervenção pedagógica realizada com alunos do segundo ano do curso Técnico de Edificações, integrado ao ensino médio, no campus Nova Venécia, que cursam a disciplina Elementos Prediais. Essa intervenção também possui características de Metodologia Ativa do tipo Aprendizagem Baseada na Resolução de Problemas (ABRP).

Resumidamente, a atividade compõe-se das seguintes ações:

a) ação 1 - apresentação da pergunta e envio do infográfico aos alunos;

b) ação 2 - gravação de vídeo pelos alunos;

c) ação 3 - apresentação dos vídeos para a turma e aula expositiva;

d) ação 4 - pesquisa com auxílio da internet;

e) ação 5 - aula de campo;

f) ação 6 - elaboração de painel interativo e participação em Fórum virtual.

$\mathrm{Na}$ ação 1, o professor deverá explicar brevemente o contexto da realização da intervenção pedagógica e serão feitas perguntas aos alunos:

Sua casa possui sistema de captação de água de chuva? Como funciona esse sistema?

Essas perguntas serão encaminhadas por meio de um infográfico, que deverá ser visualizado pelos alunos durante a aula, no laboratório de informática, ou em casa.

Para a ação 2, o professor definirá como atividade a ser desenvolvida na próxima aula, que os alunos gravem um 
vídeo com o telefone celular e postem esse vídeo no youtube, mostrando o sistema de captação de água de chuva da casa onde moram, ou de alguma casa que escolherem, e respondam (em grupos de 04 ou 05 alunos) às seguintes perguntas:

a) como é feita a captação e para onde é encaminhada a água de chuva do telhado de sua casa?

b) já houve enchente na sua rua ou bairro?

c) a rua e o bairro onde você mora são pavimentados? Em caso afirmativo, qual o tipo de pavimentação? Existe rede de drenagem de águas pluviais?

d) existe algum rio, brejo, lagoa, ou córrego próximo de sua casa?

e) qual a superfície (em metros quadrados) do telhado de sua casa e qual o material da cobertura?

f) qual é o consumo mensal de água estimado (em metros cúbicos) da residência? (observar a medição realizada pela companhia de água).

$\mathrm{Na}$ aula seguinte, na ação 3 , os alunos deverão apresentar os vídeos e discutir com a turma as respostas para essas perguntas. $\mathrm{O}$ tempo para apresentação e discussão com a turma será de 10 minutos para cada grupo. A partir das apresentações dos alunos e da discussão iniciada, serão apresentados em aula, pelo professor, os conceitos de sustentabilidade e os principais elementos que podem ser adotados para diminuir o consumo de água e de energia e melhorar os indicadores de sustentabilidade nas edificações, em especial, do sistema de captação e reuso de água de chuvas para fins não potáveis.

Posteriormente, na ação 4, os grupos de alunos já formados deverão pesquisar as seguintes informações na internet: a) identificar o índice pluviométrico da região onde a edificação está localizada;

b) identificar a bacia hidrográfica em que se localiza a casa escolhida pelo grupo;

c) pesquisar na internet $\mathrm{e}$ assistir vídeos sobre como funciona um sistema de captação e reúso de água de chuva;

d) informar qual o material utilizado para fabricação das peças utilizadas em sistemas de captação e reúso de água de chuva;

e) calcular a área de captação do telhado da casa escolhida e identificar o tipo de telha utilizada;

f) calcular o volume de água de chuva que poderá ser captada e armazenado pelo telhado da casa escolhida, considerando a NBR $15527 / 2019$.

Na sequência, na ação 5 , será feita uma visita de campo em uma edificação para conhecer, na prática, o funcionamento de um sistema de captação e reúso de água de chuva.

Por fim, na ação 6, os grupos deverão construir um painel colaborativo (padlet.com) e postarão tópicos (imagens, textos, vídeos gravados) mostrando o desenvolvimento das etapas indicadas pelo professor para o trabalho e também participarão de um Fórum de discussão em que deverão responder à seguinte pergunta: $O$ que deve ser feito para que as edificações projetadas em nossa cidade causem menos impacto ao meio ambiente?

Serão previstas 05 semanas, com um total de 10 aulas de 50 minutos, para o desenvolvimento da intervenção pedagógica. A aula de campo está prevista para ocorrer no contra turno, durante o período matutino. 


\section{RESULTADOS E DISCUSSÃO}

Durante a realização desse trabalho, apurou-se que o tema educação para a sustentabilidade, bem como o conteúdo reúso de água de chuva para fins não potáveis, encontram um terreno fértil para sua eventual aplicação no Curso Técnico de Edificações, tendo em vista as diferentes disciplinas que abordam direta ou indiretamente esse assunto.

Uma breve consulta aos noticiários nacionais e internacionais, que mostram com frequência as consequências das ações humanas no meio ambiente, reforça a importância e a urgência em discutir e ensinar formas de se projetar edifícios mais eficientes e menos consumidores de recursos naturais.

A prática pedagógica proposta nesta pesquisa defende a redução no consumo de insumos e de energia, bem como o protagonismo dos alunos. Esses princípios são encontrados e defendidos por Lima (2003) e são parte da segunda matriz interpretativa de sustentabilidade.

Os acontecimentos decorrentes da pandemia do vírus Covid-19 durante o ano de 2020 alteraram a rotina de professores e alunos, resultando na suspensão de atividades presenciais e trazendo à tona a utilização de Atividades Pedagógicas Não Presenciais (APNP), viabilizadas com a utilização da plataforma AVA / Moodle.

Essa situação demandou a adaptação no planejamento dessa prática pedagógica, que inicialmente previa a realização da intervenção, e posteriormente a esses acontecimentos, passou a ser apenas propositiva.

Portanto, as etapas finais de coleta, análise e interpretação de dados não foram avaliadas nesse trabalho, sendo propostas apenas os modelos e mecanismo para sua obtenção.

Atualmente ainda existem incertezas com relação ao retorno da rotina escolar e das aulas presenciais. Por isso, dependendo se as práticas de ensino à distância forem (parcialmente) incorporadas à vida escolar, a atividade descrita nessa pesquisa poderá demandar novos ajustes para que ela possa ser aplicada.

\section{CONCLUSÕES}

Conforme indicado nesse trabalho, diferentes autores argumentam que o Brasil possui clima favorável para aplicação da tecnologia de captação e reúso de água de chuva. Apesar disso, essa prática ainda não é aplicada em grande escala, o que justifica a necessidade de pesquisar e ensinar sobre esse assunto aqui apresentado.

Com relação ao embasamento teórico, tanto a Pedagogia Progressista Libertadora de Paulo Freire, quanto a teoria sociointeracionista de Vygotsky, e o conceito de "educação para a sustentabilidade", defendido por Lima (2003) se entrelaçam e servem de argamassa para a construção dos fundamentos teóricos e dos instrumentos de coleta de dados dessa intervenção pedagógica.

Da mesma maneira, o paradigma da sociedade da informação e da cibercultura, e seu desdobramento na atual geração digital, (hiperconectada e estimulada a produzir seu próprio conteúdo) também foi referência nessa pesquisa.

Apesar de não ter sido possível executar a metodologia proposta devido à pandemia do Covid-19, esse trabalho mostrou que a aplicação da intervenção pedagógica proposta é viável, tendo elencado o embasamento teórico, a metodologia e as ações necessárias para sua concretização. Espera-se que, no futuro, essa intervenção planejada seja integramente aplicada em disciplinas do curso técnico e, assim, possa passar por eventuais ajustes que se fizerem necessários durante sua concretização. 
Pesquisas posteriores poderão complementar a intervenção apresentada, propondo, por exemplo, a construção por parte dos alunos, de um protótipo para captação de água de chuva; ou complementando o sistema de reúso de água de chuva com a captação proveniente da drenagem de aparelhos de ar condicionado.

Por fim, pretende-se que essa prática pedagógica descrita sirva de inspiração para outras disciplinas do Ensino Médio e proporcione o despertar crítico dos alunos para a educação para a sustentabilidade.

\section{REFERÊNCIAS}

\section{ASSOCIAÇÃO BRASILEIRA DE} NORMAS TÉCNICAS. NBR 15527:

Aproveitamento de água de chuva de coberturas para fins não potáveis: requisitos. Rio de Janeiro, 2019.

BRANDÃO, João Luiz Boccia; MARCON, Priscila. Análise dos métodos de dimensionamento de reservatórios de águas pluviais sugeridos pela NBR 15527/07 com base na simulação diária.

Eng Sanit Ambient, v. 23 n. 6, 2018, p. 1031-1041. Disponível em: https:/www.scielo.br/scielo.php?script=sci arttext\&pid $=$ S1413$\overline{4} 1522018000601031 \& \operatorname{lng}=$ pt\&nrm=iso. Acesso em: 09 jul. 2020.

\section{BRASIL. Base Nacional Comum}

Curricular: educação é a base. Brasília. 2017. Disponível em: $\mathrm{http}$ //basenacionalcomum.mec.gov.br/ima ges/BNCC_EI_EF_110518_versaofinal_sit e.pdf/. Acesso em: $\overline{2} 0$ nov. 2019.

CARVALHO JÚNIOR, Roberto de. Instalações prediais hidráulicosanitárias: princípios básicos para elaboração de projetos. 2.ed. São Paulo: Blucher, 2016. 286 p.
Cálculo da colheita da água de chuva e o sistema Mano. [S.1.: 2016], 2016. 1 vídeo (3min 27seg). Publicado pelo canal Planetaria. Português. Disponível em: https://www.youtube.com/watch? $\mathrm{v}=\mathrm{SDYp}$ o6pqAtA\&feature $=$ emb_logo. Acesso em: 19 abr. 2020.

Cisterna Vertical Tecnotri - Palestra Conchuva. [S.1.: 2016], 2016. 1 vídeo (22min 09seg). Publicado pelo canal useaguadechuva. Tecnotri apresentado por Maurício Scorteganha. Português.

Disponível em:

https://www.youtube.com/watch? $\mathrm{v}=\mathrm{vxWz}$ 2cCD2EA\&feature $=$ emb_logo. Acesso em: 19 abr. 2020.

Como fazer um sistema para captar água da chuva. [S.1.: 2015], 2015. 1 vídeo (5min $55 \mathrm{seg}$ ). Publicado pelo canal Recicloteca Estudos Educação Sócioambiental.

Português. Disponível em: https://www.youtube.com/watch?v=YbDM div30ms\&feature $=$ emb_logo. Acesso em: 19 abr. 2020.

CORBELLA, Oscar; CORNER, Viviane. Manual de arquitetura bioclimática tropical. Rio de Janeiro: Revan, 2011.

DAMIANI, M. F. et al. Discutindo pesquisas do tipo intervenção pedagógica. Cadernos de Educação, Pelotas (FaE/UFPel), n. 45, p. 57-67, maio/ago. 2013. Disponível em: https://periodicos.ufpel.edu.br/ojs2/index.p $\mathrm{hp} /$ caduc/article/view/3822. Acesso em: 08 mar. 2020.

\section{ECYCLE. Captação de água da chuva:} conheça as vantagens e cuidados necessários para uso da cisterna. c2020. Disponível em:

https://www.ecycle.com.br/3301-captacaode-agua-da-chuva-aproveitamento-sistemacisternas-como-captar-armazenar-coletarpara-aproveitar-vantagens-coletormodelos-cisterna-ecologica-aproveitandocoleta-pluvial-armazenamento-caseiro- 
residencial-como-onde-encontrar-comprar. Acesso em: 14 abr. 2020.

FINKLER, Raquel. Planejamento, manejo e gestão de bacias: unidade 1 a bacia hidrográfica (apostila). Disponível em:

http:/capacitacao.ana.gov.br/conhecerh/ha ndle/ana/82. Acesso em: 30 jan. 2020.

\section{FLOW DESENVOLVIMENTO} SUSTENTÁVEL E CONSCIENTE. Sistemas de Captação da Água da Chuva. São Paulo, 2020. Disponível em: http://www.flowsustentavel.com.br/produt o-sistemas-de-captacao-da-agua-dachuva.php. Acesso em: 14 abr. 2020.

FREIRE, Paulo. Pedagogia da autonomia: saberes necessários à prática educativa. 25. ed. São Paulo: Paz e Terra, 2002. Disponível em:

http://forumeja.org.br/files/Autonomia.pdf. Acesso em: 20 nov. 2019.

\section{GIL, Antônio Carlos. Como Elaborar} Projetos de Pesquisa. 4. ed. São Paulo: Atlas, 2002.

GÜNTHER, Hartmut. Pesquisa Qualitativa Versus Pesquisa Quantitativa: Esta É a Questão? Psicologia: Teoria e Pesquisa, Brasília, v. 22, n. 2, p. 201-210, mai./ago. 2006.

INSTITUTO CAPIXABA DE PESQUISA ASSISTENCIA TÉCNICA E EXTENSÃO RURAL. Média anual de precipitação (1984 a 2014). Vitória: IDAF, 2020. 1 mapa. Escala gráfica, color. Disponível em:

https://meteorologia.incaper.es.gov.br/map as-de-chuva-normal-climatologica-album. Acesso em: 14 abr. 2020.

LAMBERTS, Roberto; DUTRA, Luciano; PEREIRA, Fernando O. R. Eficiência Energética na Arquitetura. 3. ed. Rio de janeiro: ELETROBRÀS/PROCEL, 2014. Disponível em: http://labeee.ufsc.br/sites/default/files/apos tilas/eficiencia_energetica_na_arquitetura. pdf. Acesso em: 06 jul. $20 \overline{2} 0$.

LAKATOS, Eva Maria; MARCONI, Marina de Andrade. Fundamentos de metodologia científica. 7. ed. São Paulo: Atlas, 2010.

LIBÂNEO, José Carlos. Didática. São Paulo: Cortez Editora, 1990.

\section{Tendências pedagógicas na}

prática escolar. In: LIBÂNEO, J. C. Democratização da escola pública. A pedagogia crítico-social dos conteúdos. São Paulo: Edições Loyola, 1993.

LIMA, Gustavo da Costa. O discurso da sustentabilidade e suas implicações para a educação. Ambiente $\S$ Sociedade, Campinas, v. VI, n. 2, jul/dez. 2003.

Disponível em:

http://www.scielo.br/scielo.php?script=sci arttext\&pid=S1414-

753X2003000300007. Acesso em: 20 nov. 2019.

\section{LUCKESI, Cipriano Carlos. O que é} mesmo o ato de avaliar a aprendizagem? Pátio. Porto alegre: ARTMED. Ano 3, n. 12 fev./abr. 2000. Disponível em: https://www.nescon.medicina.ufmg.br/bibl ioteca/imagem/2511.pdf. Acesso em: 20 nov. 2019.

\section{NAÇÕES UNIDAS BRASIL. Objetivos} de Desenvolvimento Sustentável, c2020. Objetivos de Desenvolvimento Sustentável 6: Água potável e saneamento.

Disponível em: https://brasil.un.org/index.php/pt-br/sdgs. Acesso em: 20 nov. 2020.

PAIVA, Anna Fernanda et al. Sala interativa: Boas ideias e um fazer diferente. 2011. 251 f. Monografia (PósGraduação em Engenharia) - Programa de Pós-Graduação em Engenharia e Especialização em Gestão do 
conhecimento e inteligência empresarial, Universidade Federal do Rio de Janeiro, Rio de Janeiro, 2011. Disponível em: https://www.researchgate.net/publication/2 36867438_SALA_INTERATIVA_BOAS IDEIAS_E_UM_FAZER_DIFERENTE. Acesso em: 15 ago. 2020.

REZENDE, Jozrael Henrique; TECEDOR, Natália. Aproveitamento de água de chuva de cobertura em edificações:

dimensionamento do reservatório pelos métodos descritos na NBR 15527. Rev. Ambient. Água, Taubaté, v. 12, n. 6, 2017, p. 1040-1053. Disponível em: https://www.scielo.br/scielo.php?script=sci arttext\&pid=S1980993X2017000601040\&lng=pt\&nrm=iso. Acesso em: 09 jul. 2020.

SANTOS, Edméa; SILVA, Marco. A pedagogia da transmissão e a sala de aula interativa. Coleção Agrinho. 2014. Disponível em:

https://www.agrinho.com.br/site/wpcontent/uploads/2014/09/2_02_Apedagogia-da-transmissao.pdf. Acesso em: 02 abr. 2020.

SEMPRESUSTENTAVEL.COM.BR. Projeto experimental de aproveitamento de água da chuva com a tecnologia da minicisterna para residência urbana. Disponível em:

http://www.sempresustentavel.com.br/hidri $\mathrm{ca} /$ minicisterna/minicisterna.htm. Acesso em: 14 abr. 2020.

SENICIATO, Tatiana; CAVASSAN, Osmar, Aulas de campo em ambientes naturais e aprendizagem em ciências: um estudo com alunos do ensino fundamental. Ciência \& Educação, [s.1.], v. 10, n. 1, p. 133-147. 2004.

SILVA, Delcio Barros da. As principais tendências pedagógicas na prática escolar brasileira e seus pressupostos de aprendizagem. Linguagens \& Cidadania, [s.1.], v. 2, n. 1, p.1-6, 11 mar. 2018.
Universidade Federal de Santa Maria.

Disponível em:

http://dx.doi.org/10.5902/1516849231515. Acesso em: 02 dez. 2019.

SILVA, Severino Felipe da; MELO

NETO, José Francisco de. Saber popular e saber científico. Revista Temas em

Educação, João Pessoa, v. 24, n. 2, p. 137 - 154, jul./dez. 2015.

Sistema para captação de água de chuva. [S.1.: 2018], 2018. 1 vídeo (5min 41seg). Português. Disponível em: https://www.youtube.com/watch?time_con tinue $=1 \& \mathrm{v}=2 \mathrm{elZIzzW}$ _VI\&feature $=\mathrm{emb} 1$ ogo. Acesso em: 19 abr. 2020.

SGARBI, Antônio Donizetti. Teorias da Aprendizagem. Disponível em: https://ava.cefor.ifes.edu.br/course/view.ph $\mathrm{p} ? \mathrm{id}=4206 \&$ sesskey $=8 \mathrm{xVAZYDyYh \# \text {secti }}$ on-4. Acesso em: 07 jul. 2020.

TOMAZ, Plinio. Aproveitamento de água de chuva de telhados em áreas urbanas para fins não potáveis: Diretrizes básicas para um projeto. In: $6^{\circ}$ Simpósio brasileiro de captação e manejo de água de chuva. 2017, Belo Horizonte. Anais... Belo Horizonte: [s.n.]. 2017. p. 1-4. Disponível em:

http://abcmac.org.br/files/simposio/6simp_ plinio_agua.pdf. Acesso em: 15 jul. 2020.

ZANETTI NETO, Giovani. Práticas de ensino, estratégias de avaliação. Apostila digital. Vitória: Ifes, 2019. Disponível em: epciencias.wordpress.com. Acesso em: 03 abr. 2020 .

APÊNDICE I - Cálculo de dimensionamento de reservatório para captação de água de chuva, conforme NBR 15527/2019 e dimensionamento da calha

Segundo a NBR 15527/2019, alguns fatores devem ser levados em conta 
para o cálculo do volume total de água de chuva captada por um telhado.

Para a Associação Brasileira de Normas Técnicas (2019), o cálculo para prever a disponibilidade teórica de água de chuva para captação depende de alguns fatores tais como: a precipitação, a área de captação, o coeficiente de escoamento superficial da cobertura e a eficiência do sistema de tratamento.

A referida norma estabelece para isso, a seguinte equação indicada na Figura 4 abaixo:

Figura 4: Equação para cálculo do volume de chuva, expresso em litros

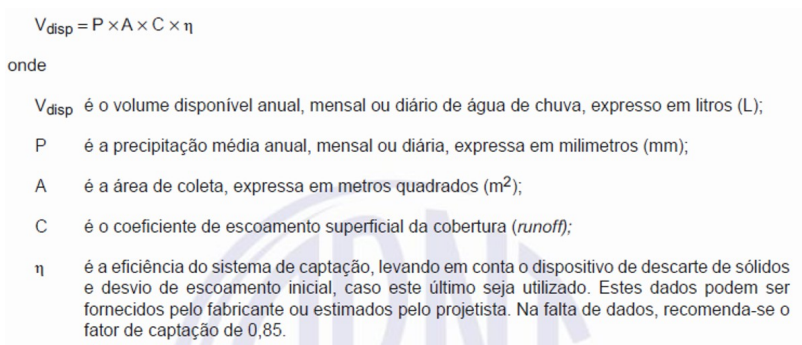

Fonte: Associação Brasileira de Normas Técnicas (2019, p. 4)

$\mathrm{Na}$ sequência abaixo, serão descritas cada uma das variáveis envolvidas no cálculo da equação.

\section{Precipitação (P)}

Para o cálculo de $\mathrm{P}$ (precipitação), deve-se considerar a média anual de chuva na região. A região de Nova Venécia possui média de $1000 \mathrm{~mm}$ de chuva por ano, ou média de $83,33 \mathrm{~mm}$ mensais, conforme Instituto Capixaba de Pesquisa Assistência Técnica e Extensão Rural (2020).

\section{Área de coleta (A)}

Para definir a área de coleta, é necessário calcular a dimensão do telhado ou cobertura existente na edificação objeto de estudo.

\section{Coeficiente de runoff ou escoamento superficial (C)}

Para Tomaz (2007), o coeficiente de runoff representa a relação entre o volume total escoado e o volume total precipitado variando conforme a superfície do telhado (tipo de telha). Segundo esse autor, os coeficientes mais comuns adotados foram descritos na Figura 5 abaixo:

Figura 5: Definição de materiais de cobertura e coeficiente de runoff

\begin{tabular}{|l|l|}
\hline Material do telhado & Coeficiente de runoff \\
\hline Telhas cerâmicas & 0,8 a 0,9 \\
\hline Telhas esmaltadas & 0,9 a 0,95 \\
\hline Telhas corrugadas de metal & 0,8 a 0,9 \\
\hline Cimento amianto & 0,8 a 0,9 \\
\hline Plástico, pvc & 0,9 a 0,95 \\
\hline
\end{tabular}

Fonte: Tomaz (2007, p. 4)

\section{Eficiência do sistema de captação ( $\eta)$}

A Eficiência do sistema de captação deve levar em conta o dispositivo de descarte de sólidos e o desvio de escoamento inicial, caso este último seja utilizado. Esses dados geralmente são fornecidos pelos fabricantes. $\mathrm{Na}$ ausência desses dados, recomenda-se utilizar o fator de captação de 0,85 .

\section{Exemplo prático de cálculo:}

Sugere-se utilizar como exemplo uma edificação localizada no município de Nova Venécia medindo $100,00 \mathrm{~m}^{2}$ de superfície de captação. Considera-se o volume mensal de chuva de $83,33 \mathrm{~mm}$. A cobertura do telhado adotada ser de telha cerâmica. 


\section{Vdisp: PxAxCxך}

$\mathrm{V}: 83,33 \times 100 \times 0,8 \times 0,85$

$\mathrm{V}: 5.666,44$ litros (mensal)

Ou seja, $5.66 \mathrm{~m}^{3}$ (metros cúbicos) de água (mensal).

Lembre-se que $1 \mathrm{~m}^{3}$ de água corresponde a 1.000,00 litros.

\section{Dimensionamento de calha para captação de água de chuva do telhado}

Para Carvalho Júnior (2016), o dimensionamento (largura, altura e cobrimento) da calha para captação de água de chuva deve observar o comprimento do telhado da edificação, conforme disposto na Figura 6 abaixo.

Figura 6: Dimensão da calha em função do comprimento do telhado

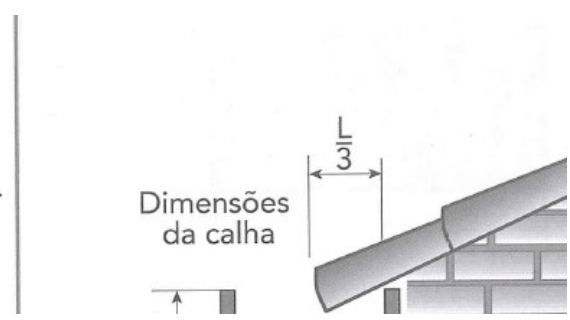

Tabela 4.5 Dimensões da calha em ft do telhado.

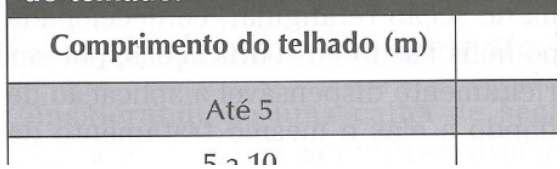

Fonte: Carvalho Júnior (2016, p. 214)

\section{APÊNDICE II - Infográficos}

As Figuras 7 e 8 abaixo, apresentam os infográficos que serão enviados aos alunos. Os referidos infográficos foram elaborados utilizando o site: https://app.genial.ly/dashboard.
Figura 7: Infográfico 1

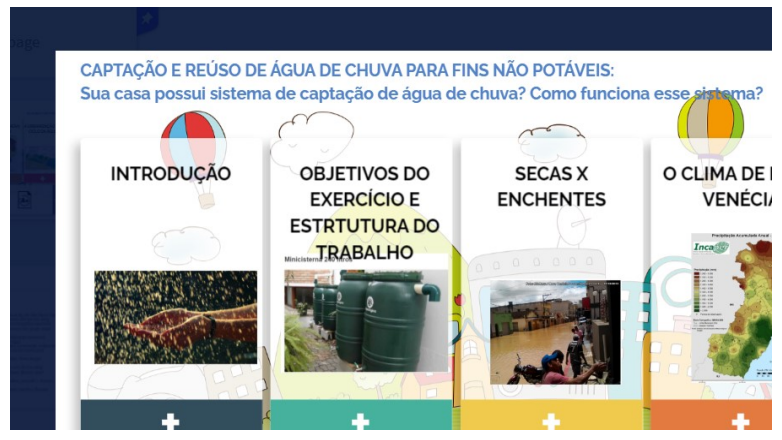

Fonte: elaborado pelo autor (2020)

Link para acesso ao infográfico 1:

https://view.genial.ly/5e946b4fe0ea7a0de3 8046b5/horizontal-infographic-reviewcaptacao-e-reuso-de-agua-de-chuva

Figura 8: Infográfico 2

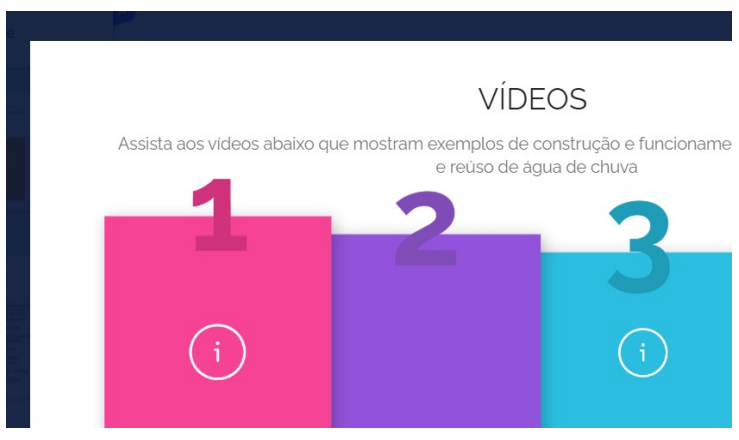

Fonte: elaborado pelo autor (2020)

Link para acesso ao infográfico 2:

https://view.genial.ly/5e7b4db29a0b5d0e0 e03499a/horizontal-infographic-reviewcaptacao-e-reuso-de-agua-de-chuva-02links-videos

\section{APÊNDICE III - Painel Interativo}

A Figura 9 abaixo, mostra o aspecto do painel interativo proposto aos alunos. $\mathrm{O}$ painel foi construído utilizando o site: https://pt-br.padlet.com. 
Figura 9: Painel interativo

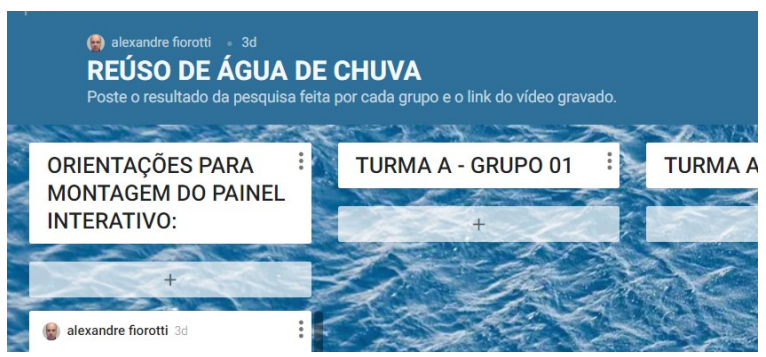

Fonte: elaborado pelo autor (2020)

Link para acesso ao painel interativo:

https://padlet.com/fiorotti_alexandre/6ttau1 qrxot8 